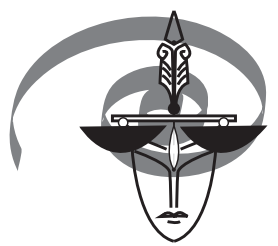

EUROPEAN

Volume $12 \cdot 2018 \cdot$ Number 1 (43)

DOI: 10.2478/ep-2018-0002

Nathan J. Gordon*
Director Academy for Scientific and Investigative Training,
Philadelphia PA, USA

Feroze B. Mohamed Director, Jefferson Integrated Magnetic Resonance Imaging Center, Professor of Radiology, Thomas Jefferson University, Adjunct Professor, Bioengineering,

Temple University, Philadelphia PA, USA

Steven M. Platek

Professor of Psychology, Georgia Gwinnett College, Lawrenceville GA, USA

Harris Ahmad

Medical Director, Innovative Medicines Development, Bristol-Myers Squibb Company, Princeton NJ, USA

J. Michael Williams

Department of Psychology, Evolutionary Cognitive Neuroscience Laboratory,

Drexel University, Philadelphia PA, USA

Scott H. Faro

Professor of Radiology, Division of Neuroradiology, Johns Hopkins School of Medicine, Baltimore MD, USA

\title{
The Effectiveness of fMRI Data when Combined with Polygraph Data
}

Эффективность сочетания данных фМРТ с данными полиграфа

Key words: Integrated Zone Comparison Technique, Polygraph, ASIT PolySuite Scoring Algorithm, Horizontal Scoring System, fMRI, Pneumo, Electro-dermal Response, Cardio

"nategordon@isope.net 


\section{Abstract}

The Integrated Zone Comparison Technique (IZCT) was utilized with computerized polygraph instrumentation and the Academy for Scientific Investigative Training's Horizontal Scoring System ASIT PolySuite algorithm, as part of a blind study in the detection of deception. This paper represents a synergy analysis of combining fMRI only deception data with each of the three individual physiological parameters that are used in polygraph. They include the electro-dermal response (EDR), pneumo, and cardio measurements. In addition, we compared the detection accuracy analysis using each single parameter by itself. The fMRI score and each individual polygraph parameter score on individual subjects were averaged to establish an overall score.

\section{Method}

As originally reported in the "Integrated Zone comparison polygraph technique accuracy with scoring algorithms" (Physiology and Behavior 2006, 87, 251-254), a blind study to assess the accuracy of the fMRI and polygraph in the detection of deception was set up using procedures developed in the polygraph profession. In that study, using random selection, half of the group was told that someone had fired a gun in the hospital and that a video in the area showed someone resembling them may have done it, the other half was instructed to actually fire a gun. Both groups were given an initial monetary payment for participating in the study, and informed that they would receive an additional monetary bonus if they were determined to be truthful when denying that they fired the gun. Thus, both the truthful and deceptive suspects were motivated toward a truthful outcome, which is consistent with real life examinations; both truthful and deceptive suspects desire to come out truthful.

A synergy analysis of combining fMRI only deception data with each of the three individual physiological parameters from the polygraph (Electro-dermal Response, Pneumo and Cardio) was performed.

Since the data from the ASIT PolySuite scoring algorithm uses cutoff thresholds of $a+13.5$ or higher for truthful determinations and a -13.5 or lower for deception, which amounts to parameter input of a $+/-4.5$, the fMRI was assigned equal input, and the following cutoff thresholds were used:

fMRI alone: $+/-4.5$

fMRI and single Polygraph parameter: $+/-9$

fMRI and all three Polygraph parameters: +/-18 
Table 1. fMRI+EDR*

\begin{tabular}{|c|c|c|c|c|c|c|c|c|}
\hline Sub & $\begin{array}{c}\text { Ground } \\
\text { Zero }\end{array}$ & $\begin{array}{c}\text { EDR } \\
\text { Score }\end{array}$ & $\begin{array}{c}\text { fMRI } \\
\text { Score }\end{array}$ & $\begin{array}{c}\text { fMRI } \\
\text { Alone } \\
\text { Determi- } \\
\text { nation }\end{array}$ & $\begin{array}{c}\text { Total } \\
\text { Score } \\
\text { fMRI+ }+ \\
\text { EDR }\end{array}$ & $\begin{array}{c}\text { Combined } \\
\text { fMRI +EDR } \\
\text { Determina- } \\
\text { tion }\end{array}$ & $\begin{array}{c}\text { Total } \\
\text { Score } \\
\text { fMRI+ } \\
\text { Poly }\end{array}$ & $\begin{array}{c}\text { Combined } \\
\text { fMRI+ POLY } \\
\text { (EDR, P, C**) } \\
\text { Determination }\end{array}$ \\
\hline PD & DI & 0 & -71 & DI & -71 & DI & -110 & DI \\
\hline KS & DI & 0 & -95 & DI & -95 & DI & -135 & DI \\
\hline $\begin{array}{l}\text { JR } \\
\mathbf{H}\end{array}$ & NDI & $+\mathbf{1 3}$ & $\mathbf{- 6 . 7 5}$ & DI & $\mathbf{6 . 2 5}$ & INC & $+\mathbf{1 9 . 2 5}$ & NDI \\
\hline $\begin{array}{c}\text { JB } \\
-\end{array}$ & NDI & -11 & +21.6 & NDI & 10.6 & NDI & +26.6 & NDI \\
\hline LH & NDI & $+\mathbf{2 1}$ & $\mathbf{0}$ & INC & $+\mathbf{2 1}$ & NDI & $+\mathbf{4 6}$ & NDI \\
\hline MC & DI & -13 & -63.45 & DI & -76.45 & DI & -87.45 & DI \\
\hline NM $\dagger$ & DI & $\mathbf{- 2 3}$ & $\mathbf{0}$ & INC & $-\mathbf{2 3}$ & DI & $\mathbf{- 5 8}$ & DI \\
\hline SM & DI & -12 & -108 & DI & -120 & DI & -131 & DI \\
\hline BB & DI & -15 & -139.05 & DI & -154.05 & DI & -171.05 & DI \\
\hline SP & NDI & +17 & +28.35 & NDI & +45.35 & NDI & +82.35 & NDI \\
\hline
\end{tabular}

(Galvanic Skin Response* = Electro-dermal Response); $\left({ }^{* *} \mathrm{P}=\right.$ Pneumo, C = Cardio) DI: Deception Indicated; NDI: No Deception Indicated; INC: Inconclusive.

\section{Important findings for Table 1}

1. When comparing fMRI data (Table 1), our data demonstrated that two subjects $(t)$ of the ten showed that fMRI alone was clearly inconclusive for the determination of truth or deception $20 \%$ of the time. In these subjects when we combined all three polygraph parameter scores (EDR, Pneumo, and Cardio) with the fMRI score the final determination of truth and deception was changed from inconclusive to concordance with ground zero fact (NDI, DI) in both of these cases. This increased accuracy by $20 \%$. These findings show that $\mathrm{fMRI}$ alone is not sufficient in $20 \%$ of the time for an accurate determination of truth (NDI) or deception (DI).

2. In one $(\downarrow)$ out of the 10 subjects, combining fMRI with EDR alone changed the status of determination of truth or deception from conclusive (NDI) to inconclusive. This data shows that in $10 \%$ of the time adding EDR score alone to fMRI score is detrimental to an accurate determination of truth and deception.

3. In one $(\downarrow)$ out of the 10 subjects, using fMRI alone made a determination of deception which was erroneous with ground zero fact.

4. The synergy of all three polygraph parameters combined with the fMRI data increased the accuracy of the test procedure by $20 \%$ over the combination of just fMRI and EDR data, and $30 \%$ over fMRI data by itself. 


\section{Table 1. Summary}

Based on our research it is vital to use fMRI data combined with all three polygraph parameters to achieve the most accurate determination of truth or deception. This was our primary claim of our patent.

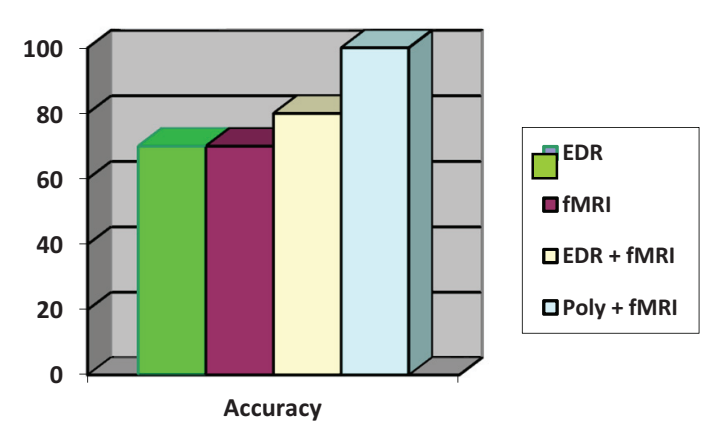

Table 2. fMRI + Pneumo

\begin{tabular}{|c|c|c|c|c|c|c|c|c|}
\hline $\begin{array}{c}\text { Subject } \\
\text { initials }\end{array}$ & $\begin{array}{c}\text { Ground } \\
\text { Zero }\end{array}$ & $\begin{array}{c}\text { Pneumo } \\
\text { Score }\end{array}$ & $\begin{array}{l}\text { fMRI } \\
\text { Score }\end{array}$ & $\begin{array}{c}\text { fMRI } \\
\text { Alone } \\
\text { Determi- } \\
\text { nation }\end{array}$ & \begin{tabular}{|c|} 
Total \\
Score \\
fMRI + \\
Pneumo
\end{tabular} & $\begin{array}{c}\text { Combined } \\
\text { fMRI + } \\
\text { Pneumo De- } \\
\text { termination }\end{array}$ & $\begin{array}{c}\text { Total } \\
\text { Score } \\
\text { fMRI + } \\
\text { Poly }\end{array}$ & \begin{tabular}{|c} 
Combined \\
fMRI + \\
POLY (EDR, \\
P, C C $^{* *}$ ) De- \\
termination
\end{tabular} \\
\hline PD & DI & -20.5 & -71 & DI & -91.5 & DI & -110 & DI \\
\hline KS & DI & 10 & -95 & $\mathrm{DI}$ & -105 & $\mathrm{D}$ & -135 & DI \\
\hline JR & DI & +8 & -6.75 & DI & 1.25 & IN & 19.25 & NDI \\
\hline JB & NDI & -4 & +21.6 & NDI & 17.6 & $\mathrm{DI}$ & +26.6 & NDI \\
\hline $\begin{array}{c}\mathbf{L H} \\
\Delta \Delta, \dagger\end{array}$ & NDI & 0 & 0 & INC & 0 & INC & +46 & NDI \\
\hline $\mathrm{MC}$ & DI & +2 & -63.45 & DI & -61.45 & DI & -87.45 & DI \\
\hline $\begin{array}{c}\mathbf{N M} \Delta \\
\mathbf{\Delta} \Delta\end{array}$ & DI & -23 & 0 & INC & -23 & DI & -58 & DI \\
\hline SM & DI & -14 & -108 & D1 & -122 & D1 & -131 & DI \\
\hline BB & DI & +5 & -139.05 & DI & -134.05 & DI & -171.05 & DI \\
\hline SP & NDI & +17 & +28.35 & NDI & 45.35 & NDI & +82.35 & NDI \\
\hline
\end{tabular}

\section{Important findings for Table 2}

1. In one $(\mathbf{\Delta})$ out of the 10 subjects, combining fMRI with Pneumo alone to fMRI alone, changed the status of determination of truth or deception from inconclusive to a concordant ground zero fact (DI) which represents a $10 \%$ increase in accuracy over fMRI alone. 
2. When combining fMRI with all three polygraph scores to fMRI alone, it changed two $(\boldsymbol{\Delta} \boldsymbol{\Delta})$ inconclusive to concordant truth (NDI, DI), and one $(\downarrow \bullet \downarrow)$ incorrect deceptive (DI) conclusion to concordant truth, which represents a $30 \%$ increase in accuracy over fMRI alone.

3. When combining fMRI with all three polygraph scores to fMRI plus pneumo alone, we changed both $(t)$ inconclusive results to concordant truth (NDI) which represents a $20 \%$ increase in accuracy.

\section{Table 2. Summary}

Combining the fMRI data with polygraph data showed the greatest increase in accuracy compared to fMRI alone or fMRI combined with Pneumo.

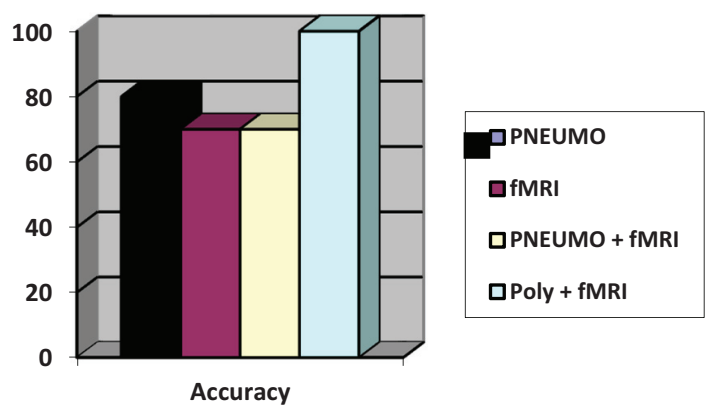

\section{Table 3. fMRI + Cardio}

\begin{tabular}{|c|c|c|c|c|c|c|c|c|}
\hline $\begin{array}{c}\text { Sub- } \\
\text { ject } \\
\text { initials }\end{array}$ & $\begin{array}{c}\text { Ground } \\
\text { Zero }\end{array}$ & $\begin{array}{c}\text { Car- } \\
\text { dio } \\
\text { Score }\end{array}$ & $\begin{array}{c}\text { fMRI } \\
\text { Score }\end{array}$ & $\begin{array}{c}\text { fMRI } \\
\text { Alone } \\
\text { Determi- } \\
\text { nation }\end{array}$ & $\begin{array}{c}\text { Total } \\
\text { Score } \\
\text { fMRI }+ \\
\text { Cardio }\end{array}$ & $\begin{array}{c}\text { Combined } \\
\text { fMRI }+ \\
\text { Cardio Der- } \\
\text { termination }\end{array}$ & $\begin{array}{c}\text { Total } \\
\text { Score } \\
\text { fMRI + } \\
\text { Poly }\end{array}$ & $\begin{array}{c}\text { Combined fMRI } \\
+ \text { POLY (EDR, } \\
\text { P, C*) Determi- } \\
\text { nation }\end{array}$ \\
\hline PD & DI & -19 & -71 & DI & -90 & DI & -110 & DI \\
\hline KS & DI & -27 & -95 & DI & -105 & DI & -135 & DI \\
\hline $\begin{array}{c}\text { JR } \\
\mathbf{\square}\end{array}$ & NDI & $+\mathbf{2}$ & $\mathbf{- 6 . 7 5}$ & DI & $+\mathbf{4 . 7 5}$ & INC & $+\mathbf{1 9 . 2 5}$ & NDI \\
\hline JB & NDI & +8 & +21.6 & NDI & +29.6 & NDI & +26.6 & NDI \\
\hline $\begin{array}{c}\text { LH } \mathbf{\Delta} \\
\dagger\end{array}$ & NDI & $+\mathbf{2 5}$ & $\mathbf{0}$ & INC & $+\mathbf{2 5}$ & NDI & $+\mathbf{4 6}$ & NDI \\
\hline MC & DI & -13 & -63.45 & DI & -76.45 & DI & -87.45 & DI \\
\hline $\begin{array}{c}\text { NM } \dagger \\
\text { DI }\end{array}$ & $\mathbf{- 9}$ & $\mathbf{0}$ & INC & $\mathbf{- 9}$ & DI & $\mathbf{- 5 8}$ & DI \\
\hline SM & DI & -7 & -108 & DI & -115 & DI & -131 & DI \\
\hline BB & DI & -8 & -139.05 & DI & -147.05 & DI & -171.05 & DI \\
\hline SP & NDI & +23.5 & +28.35 & NDI & 51.85 & NDI & +82.35 & NDI \\
\hline
\end{tabular}


1. In two $(\mathbf{\Delta})$ out of the 10 subjects, combining fMRI with cardio alone to fMRI alone, changed the status of determination of truth or deception from inconclusive to a concordant ground zero fact (NDI) which represents a $20 \%$ increase in accuracy over fMRI alone.

2. When combining fMRI with all three polygraph scores to fMRI alone, we changed the two $(t)$ inconclusive results to concordant truth which represents a $20 \%$ increase in accuracy over fMRI alone.

3. When combining fMRI with all three polygraph scores to fMRI plus cardio alone, we changed one ( $\mathbf{a})$ inconclusive to concordant truth (NDI) which represents a $10 \%$ increase in accuracy.

4. When combining fMRI with all three polygraph scores to fMRI alone, we changed the one ( $\mathbf{a})$ incorrect deceptive (DI) results to concordant truth which represents a $10 \%$ increase in False/Positive accuracy over fMRI alone.

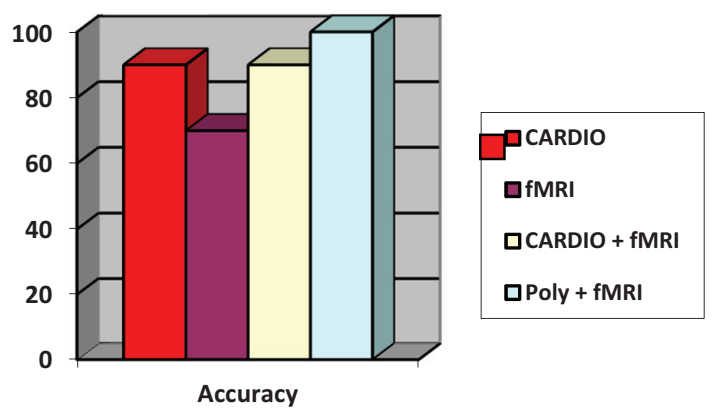

Once again this shows the importance of combining fMRI data with the data of all three polygraph parameters.

Looking at the individual accuracy of each of three polygraph parameters alone we found that the EDR had 70\% accuracy (2 Inconclusives and 1 False/Positive), the Pneumo had $80 \%$ accuracy (2 Inconclusives) and the Cardio had 90\% accuracy (1 Inconclusive). 


\section{Conclusion}

Based on these results of this study it appears vital to use fMRI combined with all three polygraph parameters to achieve the most accurate determination of truth or deception.

In addition, it raises a serious question about the validity of weighting one polygraph parameter such as the EDR over the other two parameters (Cardio and Pneumo), as in the case of some computerized algorithms and some manual scoring systems. 